\title{
Review on epidemiological features of Mycobaterium bovis at the human, cattle and wildlife interface in Ethiopia
}

\begin{abstract}
Summary
Mycobacterium bovis is an intracellular, non-motile, facultative, weakly Grampositive acid-fast bacillus which belongs to the Mycobacterium tuberculosis complex. The pathogen affects all age groups of susceptible hosts of domestic, wild animals and human. In cattle, Bovine tuberculosis is one of the endemic chronic diseases of cattle that have long been recorded in Ethiopia. The disease has been reported from several parts of the country mainly based on tuberculin tests and abattoir inspections. Studies undertaken in several parts of the country have indicated that, the individual animal and the herd level prevalence rate of Bovine tuberculosis is ranging from $0.8 \%$ to $42.5 \%$ and from $7.02 \%$ to $79.3 \%$ respectively. Whereas the prevalence of the disease reported from different slaughterhouses of the country varies from $1.5 \%$ to $24.7 \%$. Mycobaterium Bovis was also confirmed to be a cause of human infections in the country. However, very little information on the extent of Mycobaterium Bovis either as an animal or human health problem are available and the current actual prevalence rate of Bovine tuberculosis at a national level is yet unknown. No infection due to Mycobaterium Bovis was reported in Ethiopia wildlife population so far. In Ethiopia, cattle breeds, age, sex, body condition score and herd size, management condition, geographical origin, consumption of raw milk and close contact to livestock are most commonly identified risk factors for spread of Mycobaterium Bovis. Although, the disease represents a potential health hazard to all susceptible hosts, the economic effects of the disease are not well studied. With the exception of few attempts like condemnation of carcass and organs during meat inspection, culling of infected animals in some government owned farms and pasteurization of milk, effective disease control strategies do not yet established in our country.
\end{abstract}

Keywords: bovine, tuberculosis, Mycobaterium bovis, susceptible hosts, risk factors, Ethiopia
Special Issue - 2018

\author{
Chaltu Muhammed,' Fekadu Seboka,' \\ Gebawo Tibesso ${ }^{2}$ \\ 'Oromia Livestock and Fisheries Development Office, Ethiopia \\ ${ }^{2}$ Oromia Agricultural Research Institute, Ethiopia
}

Correspondence: Gebawo Tibesso, Ziway Fisheries Resource Research Center, P O Box 229, Ziway, Oromia, Ethiopia, Tel

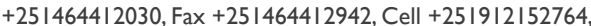
Email nadhi2521@yahoo.com

Received: September 03,2017 | Published: September 28, 2018

\section{Introduction}

Mycobaterium bovis is among a pathogenic species which belongs to the Mycobacterium tuberculosis complex (MTBC), a group of genetically closely related mycobacteria. ${ }^{1}$ Mycobaterium bovis (M. bovis) is an intracellular, non-motile, facultative, weakly Gram-positive acid-fast bacillus. ${ }^{2}$ The MTBC sub-group also comprises $M$. tuberculosis, M. africanum, M. canettii, $M$. pinnipedii, M. microti and $M$. caprae that are generally regarded as host adapted but with the ability to spill over into other species. Mycobaterium bovis is the primary cause of bovine tuberculosis (BTB). M. tuberculosis, $M$. africanum, M. caprae and $M$. canettii are human pathogens. $M$. caprae which causes infection in goats has been initially classified as subspecies of $M$. bovis but was recently recognized as a species on its own. M. microti affects rodents and M. pinnipedii have been isolated from seals. ${ }^{2}$ Mycobaterium bovis has an exceptionally wide range of mammalian hosts and affects all age groups of susceptible hosts of domestic, wild animals and human. ${ }^{2}$ Cattle are the most common maintenance host for $M$. bovis infection from which transmission can occur to wildlife, or people animals. ${ }^{3}$

Opossums, badgers and bison are known maintenance hosts in differen European countries and African buffalo, Kudu, deer, lechwe and wild boar have been classified as maintenance hosts for M. bovis in Africa. ${ }^{4}$ Many susceptible animals and wildlife species, including man are spillover hosts in which infection is not self- maintaining. ${ }^{5}$ Bovine tuberculosis is one of the chronic bacterial diseases of animals that can take a variable amount of time (from a few weeks to a life time) to develop from infection to clinical disease and to become infectious to other animals. ${ }^{2,6}$ The disease mostly affects cattle and rarely other species of domestic animals. ${ }^{7}$ The name "Tuberculosis" comes from the nodules, called 'tubercles', which form in the lymph nodes of affected animals and the disease is characterized by the progressive development of specific granulomatous lesions of tubercles in affected tissues and organs. ${ }^{2}$

In addition to domestic animals, wild mammals can also be infected with BTB. The list of wildlife species around the world from which $M$. bovis has been isolated is estimated to be more than 40 free-ranging wild animal species. ${ }^{8,9}$ Among African countries, the most detailed data has been collected in Southern Africa, Uganda and Tanzania. However, the status of BTB in wildlife is still lacking and need further studies in most African countries. ${ }^{10,11}$ Mycobaterium bovis is also the most frequent cause of zoonotic tuberculosis (TB) in humans. ${ }^{5}$ Tuberculosis, which is primarily a respiratory disease, is responsible for the death of more people each year than any other infectious disease. The World Health Organization (WHO) reported 9.2 million new cases of human TB and 2 million deaths in 2006, with Sub-Saharan Africa having the highest annual risk of infection with tuberculosis, probably aggravated by the expanding Human Immunodeficiency Virus (HIV) epidemic and increasing drug resistance. ${ }^{10}$ Global prevalence of human TB due to $M$. bovis has been estimated at $3.1 \%$ of all human TB cases accounting for $2.1 \%$ of pulmonary and $9.4 \%$ of extra pulmonary TB cases. ${ }^{12}$ The WHO also reported in 2004 that $0.4-$ $10 \%$ of sputum isolates from patients in African countries could be M. bovis. ${ }^{13}$ Bovine tuberculosis is an endemic disease of cattle in Ethiopia and the disease has been reported from several regions of the country based on tuberculin tests $^{7,14}$ and abattoir inspections. ${ }^{15-17}$ In Ethiopia, M. bovis was also isolated from sputum and fine needle aspirate of human and confirmed to be a cause of human TB cases. ${ }^{18-20}$ On the other hand, no infection due to $M$. bovis was reported in Ethiopian wildlife populations so far and the status of the disease in wildlife populations is yet unknown. ${ }^{21}$ On other side there is knowledge gap 
concerning indication of Epidemiological Features of Mycobaterium Bovis at the Human, Cattle and Wildlife Interface in Ethiopia which will play important role in controlling of the disease. So this review aims to elaborate the status of $M$. bovis in cattle, wildlife and human populations, to identify risk factors considered in studies conducted so far and to identify the knowledge gaps in the epidemiology of M. bovis in Ethiopia.

\section{Prevalence of Mycobacterium Bovis in Ethiopia}

In Ethiopia, isolation of $M$. bovis was done mainly from domestic animal species and humans. In cattle, most of the studies conducted on Bovine TB so far have been focusing on the highlands of Central Ethiopia while a lot of areas especially the pastoral lowlands are not covered by adequate studies. ${ }^{15,22}$ The distribution of the disease varies from place to place based on the production systems under which livestock are managed. ${ }^{22}$

Several studies undertaken in different parts of the country have confirmed the endemic nature of the disease in Ethiopian cattle populations. The individual animal and herd level prevalence rate of Bovine TB is ranging from $0.8 \%$ to $42.5 \%$ and from $7.02 \%$ to $79.3 \%$ respectively. ${ }^{23-25}$ Studies reports have shown that, both animal and herd level prevalence rate of Bovine TB is higher in intensive production system than in animal managed under traditional husbandry system. ${ }^{22-26}$ Moreover; in Ethiopia, exotic and cross breeds were found to be more susceptible than local breeds to $M$. bovis with manifestation of high prevalence rates of the disease. ${ }^{22-27}$ Mycobacterium bovis also infects other species of domestic animals which are considered as spillover hosts such as: sheep, goats, equines, camels, pigs, dogs and cats. Equines and sheep are rarely infected by the disease and pigs can also acquire the infection when fed with infected milk or milk by-products. ${ }^{3}$ Studies reports from few parts of the country have also indicated the infection of small ruminants due to M. bovis. Tschopp et al., ${ }^{28}$ and Mamo et al., ${ }^{29}$ were reported the prevalence of $M$. bovis at $0.74 \%$, and $5.29 \%$ in small ruminants based on tuberculin test. International Livestock Research Institute (ILRI) and Deresa et al., ${ }^{30}$ also found 3.5\% and $4.2 \%$ prevalence of $M$. bovis in Ethiopian goats and in caprine respectively. In addition, Gumi et al., ${ }^{31}$ reported the infection of $M$. bovis in camel prevalence rate of $0.2 \%$. The role of Bovine TB causing tuberculosis in humans has not been studied adequately. However, very few studies have indicated the isolation of the causal agent of Bovine TB from humans in Ethiopia. Teshome, ${ }^{32} \mathrm{Kiros},{ }^{18}$ Asseged et al., ${ }^{33}$ Kidane et al., ${ }^{19}$ Regassa $^{14}$ reported that $M$. bovis and other group of microbacteria were found to be a cause for tuberculous lymphadenitis in humans. Thus, the correlation between the prevalence of $M$. bovis infection in humans and that of cattle populations highlights the potential threat of this disease for humans, most notably in developing countries like Ethiopia, where there is a habit of drinking raw milk and close contact with animal are a common practices. ${ }^{34,35}$ Besides being a potential zoonotic threat through consumption of raw animal products and close animal-human contact, the disease can have major economic impacts on national livestock sector. ${ }^{36}$ Despite the isolation of M. bovis from domestic animal and human, no infection due to M. bovis was reported in Ethiopian wildlife populations so far and the status of the disease in wildlife populations is yet unknown. ${ }^{15,21}$ Moreover; the information on the epidemiology of the disease is scarce and the current actual prevalence rate of the disease is not well established at a national level. This is mainly due to the absence of disease surveillance, insufficient laboratory capacity and the lack of veterinary expertise. ${ }^{7,15}$

\section{Bovine tuberculosis in cattle}

Bovine tuberculosis has long been reported in Ethiopian cattle populations. Transmission of Bovine TB can be either direct, through close contact between infected and susceptible individuals, or indirect from exposure to viable bacteria in a contaminated environment. ${ }^{37}$ Respiratory and alimentary or oral routes are routes of infection where transmission between cattle is mostly thought to occur by inhalation of contaminated aerosol. ${ }^{38}$ Infection can also occur via the gastro-intestinal tract when animals ingest contaminated food, water, soil or milk. ${ }^{6}$ Cutaneous, genital, and vertical (congenital) transmissions have been seen but are rare. ${ }^{37}$ The disease can also transmitted indirectly through infected flightless vectors, winged vectors or mechanical vectors. ${ }^{6}$ Nowadays there are a number of diagnostic tests available to detect $M$. bovis in cattle. In Ethiopia, detection of Bovine TB is carried out most commonly based on the tuberculin skin testing, abattoir meat inspection and very rarely on bacteriological techniques. ${ }^{7}$ Mycobaterium bovis multiplies quite slowly and also there are usually low in number. These make $M$. bovis hard to detect either directly in clinical sample from live animals or by growing it in the laboratory organisms in clinical sample. Therefore techniques looking directly for the organisms or its DNA, such as culture or polymerase chain reaction (PCR), are insensitive. Hence, primary diagnostic tests for M. bovis rely on detecting the immune response of the host to the organism using skin tests and gamma interferon. ${ }^{2}$ Single intradermal tuberculin skin test (SIDT) and comparative skin test (CIDT) remain the international field diagnosis methods of Bovine TB. The skin test is the central ante mortem diagnostic test applied to the diagnosis of tuberculosis in cattle. Pivotal for the intradermal skin test are the purified protein derivative (PPD) tuberculins. Tuberculin skin test is based upon the measurement of a delayed type hypersensitivity response to intradermally injected tuberculins. ${ }^{3}$ The cellular response, the pathology and clinical signs seen with the disease on cattle are associated with the body's immune response to the bacteria and not solely with the pathogenicity of the bacteria itself. ${ }^{2}$ Both SIDT and CIDT are typically performed either in the neck or caudal tail fold. The decision which test to apply is influenced by a variety of considerations which include the prevalence of disease and the exposure of cattle to other mycobacteria. Although CIDT has more specificity and sensitivity than SIDT, these tests seem to lack sensitivity. ${ }^{3}$ Sensitivity depends on the potency and dose of tuberculin administered, the post infection interval, desensitization, postpartum immune suppression and observer variation and the estimates of the sensitivity of tuberculin tests ranged from 68 to $95 \%$. $^{39}$

\section{Detection of bovine TB prevalence in different production systems based on tuberculin skin tests}

The production systems under which livestock are managed may have a significant influence on distribution of animal tuberculosis. ${ }^{40}$ The prevalence of Bovine TB is different in various production systems due to environmental and management factors (malnutrition, pregnancy and concurrent infection) that may suppress the immune responsiveness. ${ }^{18,41}$ Livestock production systems are identified on the basis of contribution of the livestock sector to the total household revenue (income and food), type and level of crop agriculture practiced, types of livestock species kept and mobility and duration of movement. ${ }^{42}$ Mode of livestock production is basically classified into three categories. These production systems include: pastoral and agro-pastoral, smallholder and intensive production systems. ${ }^{7}$ The prevalence of Bovine TB in Ethiopia studied based on the different production systems are stated herein.

Pastoral and agro pastoral production systems: In pastoral areas, livelihoods of the people entirely depend on extensive livestock production with little or no cropping. ${ }^{43}$ In Ethiopia, the pastoral production systems are practiced in the arid and semi-arid lowland areas. The numbers of livestock in pastoral areas account for $42 \%$ of the country's livestock in the lowland arid and semiarid regions. ${ }^{42}$ Agro pastoral production systems are mainly practiced in the highland agro - ecology of the country, where there is mixed crop - livestock production (integrated extensive production system). ${ }^{44}$ This production system holds about $85 \%$ of the total livestock population of the country. In this production systems, crop and livestock production are both important activities. However, most notably crop production is the primary target. Here a small number of herds are reared for seasonal milk and meat productions under traditional animal husbandry practice with low hygienic standards..$^{42}$ In both production systems drinking raw milk is a common practice, in rural areas in particular, which may expose the community to contagious diseases most notably Bovine TB. Despite the presence of a huge livestock population in this production system, the actual prevalence of BTB is not yet known. The remoteness of sites, the difficult logistics combined with inadequate veterinary infrastructures and poor security in these areas are contributing factors to the scarcity of research studies. ${ }^{7,42}$ In Ethiopia, few prevalence studies were conducted in cattle kept under traditional husbandry system. According to these study results, the animal level prevalence of Bovine TB in pastoral and agro pastoral production systems varies from $0.8 \%$ in Hamer pastoral areas ${ }^{21}$ to $15.8 \%$ in Bokoji and Tiyo (Arsi Zone) of highlands agro pastoral districts. ${ }^{45}$ Whereas the herd level prevalence rates varies from $7.02 \%$ in Boji (West Wellega $)^{46}$ to $54.1 \%$ Amibara districts of Afar pastoral region. ${ }^{29}$ Among very few studies undertaken in the pastoral and agro pastoral production system (based on tuberculin skin test), the individual animal and herd level prevalence rates of Bovine TB are summarized in Table $1 \& 2$. 
Table I Individual animal level prevalence of BTB in traditional managed husbandry system

\begin{tabular}{|c|c|c|}
\hline Study area & Prevalence (\%) & Reference \\
\hline Afambo $_{*}$ & 6.6 & Mamo et al., ${ }^{30}$ \\
\hline Ambo and Toke Kutaye ${ }_{*}$ & I & Tamiru et al., ${ }^{26}$ \\
\hline Amibara & I4.I & Mamo et al., ${ }^{30}$ \\
\hline $\begin{array}{l}\text { Arsi Negele and } \\
\text { Shashamane }_{*}\end{array}$ & 8.9 & Dinka \& Asmamaw, ${ }^{47}$ \\
\hline Boji. & 1.6 & Laval \& Ameni, ${ }^{93}$ \\
\hline Bokoji and Tiyo & 15.8 & Dinka \& Asmamaw, ${ }^{47}$ \\
\hline Chifra & 1.9 & Mamo et al., ${ }^{30}$ \\
\hline Dubti & 6.6 & Mamo et al., ${ }^{30}$ \\
\hline Filtu & 2 & Gumi et al., ${ }^{32}$ \\
\hline Hamer & 0.8 & Tschoop et al.,20I I \\
\hline Liben and Goro-Dola & 5.5 & Gumi et al., ${ }^{32}$ \\
\hline
\end{tabular}

Comparative intradermal skin test was used in all studies and result was interpreted at $>4 \mathrm{~mm}$ cut-off. *Agro pastoral production system

Table 2 Herd level prevalence of bovine TB in pastoral and agro - pastora production system

\begin{tabular}{lll}
\hline Study area & Prevalence (\%) & Reference \\
\hline Afambo & 46.2 & Mamo et al., ${ }^{30}$ \\
Ambo and Toke Kutaye & 7.02 & Tamiru et al., $^{26}$ \\
Amibara & 54.1 & Mamo et al., ${ }^{30}$ \\
Boji & 19 & Laval \& Ameni, ${ }^{93}$ \\
Chifra & 11.8 & Mamo et al., ${ }^{30}$ \\
Dubti & 25 & Mamo et al., ${ }^{30}$ \\
Hamer & 33.3 & Tschoop et al., 20I I \\
Liben and Goro-Dola & 41.9 & Gumi et al., ${ }^{32}$ \\
\hline
\end{tabular}

Smallholder production systems: Smallholder production systems is dominantly in highland areas near towns where dairy animals are reared for subsistence and/or commercial milk production purposes through the introduction of exotic breeds..$^{22,42}$ However, in contrast, this introduction of exotic and cross-bred cattle, into the central highlands of Ethiopia in particular has created conducive environment for the spread of Bovine TB. ${ }^{7}$ Although there is some cross - sectional studies, prevalence studies on Bovine TB have not been conducted adequately under this production system. In smallholder production system, the individual animal prevalence of the Bovine TB ranging from $4.3 \%$ in Dilla ${ }^{47}$ to $13.5 \%$ in Central highlands of Ethiopia (Table 3) (Table 4). ${ }^{22}$

Table 3 Individual animal prevalence of BTB in smallholder production

\begin{tabular}{lll}
\hline Study area & Prevalence (\%) & Reference \\
\hline Adama & II & Ameni \& Erkihun, ${ }^{117}$ \\
Central highlands of Ethiopia & 13.5 & Ameni et al., ${ }^{23}$ \\
Dilla & 4.3 & Romha et al., ${ }^{48}$ \\
Mekelle & 11.3 & Zeru et al., ${ }^{91}$ \\
North Gondar & 7.1 & Mohammed et al., ${ }^{78}$ \\
Sululta & 11.4 & Biru et al., ${ }^{79}$ \\
Wuchale Jida & 7.9 & Ameni et al., \\
\hline
\end{tabular}

Comparative intradermal skin test was used in all studies and result was interpreted at $>4 \mathrm{~mm}$ cut-off
Table 4 Herd level prevalence of BTB in smallholder dairy farms

\begin{tabular}{lll}
\hline Study area & Prevalence (\%) & Reference \\
\hline Adama & 15 & Ameni \& Erkihun, ${ }^{117}$ \\
Dilla & 15.3 & Romha et al., ${ }^{48}$ \\
Mekelle & 20 & Zeru et al.,20I4 \\
North Gondar & 21 & Mohammed et al., ${ }^{78}$ \\
Sululta & 20 & Biru et al., ${ }^{79}$ \\
\hline
\end{tabular}

Intensive production system: Although some few intensive feed lots exist, dairy production is the major practice of this system, which is targeted for the production of milk and milk products. The total number of the cattle population under this production system is insignificant compared to the national livestock population. ${ }^{26,33}$ Intensive farming systems are usually performed in peri-urban and/or urban areas and they are the main source of milk for the city dwellers.22 As compared to both extensive and smallholder production system, higher prevalence rates have been reported from intensive farming systems which are characterized by high numbers of dairy farms, exotic breeds and their crosses. ${ }^{22-27}$ In intensive dairy farms, animal level prevalence of Bovine TB is ranging from $10.1 \%$ to $42.5 \% .{ }^{14}$ Individual and herd level prevalence rates of Bovine TB reported from different intensive farms are summarized in Table $5 \& 6$.

Table 5 Individual animal level prevalence of BTB in intensive dairy farms

\begin{tabular}{lll}
\hline Study area & Prevalence (\%) & Reference \\
\hline Addis Ababa & 18.7 & Shitaye et al., ${ }^{17}$ \\
Addis Ababa & 23.7 & Elias et al., $^{27}$ \\
Addis Ababa & 34.1 & Tsegaye et al., $^{28}$ \\
Addis Ababa & 12.2 & Firdessa et al., \\
Debre Zeit & 20.07 & Firdessa et al., \\
Holeta & 10.1 & Firdessa et al., \\
Sebeta & 42.5 & Firdessa et al., \\
Sendafa & 31.2 & Firdessa et al., \\
Sululta & 37.7 & Firdessa et al., \\
\hline
\end{tabular}

In all studies, comparative intradermal skin test was used and the result was interpreted at $>4 \mathrm{~mm}$ cut-off

Table 6 Herd level prevalence of BTB in intensive dairy farms

\begin{tabular}{ll}
\hline Study area & Prevalence (\%) \\
\hline Addis Ababa & 33.3 \\
Debre Zeit & 77.7 \\
Holeta & 61.2 \\
Sebeta & 70.3 \\
Sendafa & 79.3 \\
Sululta & 41.3
\end{tabular}

\section{Meat inspection and detection of tuberculous lesions at slaughterhouses}

Abattoir surveillance can be a cost effective method for surveying TB in animals. In addition to tuberculin skin testing, detection of $M$. bovis also carried out on the basis of abattoir meat inspection. However this diagnostic method can also lack sensitivity. ${ }^{48}$ In Ethiopia, the routine abattoir inspection was conducted according to the method developed by the meat inspector and quarantine division of the ministry of agriculture. ${ }^{49}$ Abattoir meat inspection at the moment remains economically affordable and valuable technique 
to detect Bovine TB in carcasses of slaughtered animals in most of African countries. ${ }^{50,51}$ Mycobaterium bovis has a wide range of target organs (lungs, gastrointestinal tract, mammary gland, kidney and reproductive organs) to infect. ${ }^{52}$ Routine abattoir inspection therefore involves visual examination and palpation of organs these organs as well as pleural lymph nodes and palpation and incision of the bronchial, mediastinal and prescapular lymph nodes. ${ }^{53}$ According to literature, in areas where disease control program is absent, up to $40 \%$ prevalence of $\mathrm{TB}$ can be detected in public abattoirs during meat inspection..$^{54}$ However, due to the manner of examination, there is a failure in correctly detect tuberculosis infection during meat inspection. It was noticed that in standard meat inspection procedure only few sites (organs) are often inspected at a glance and smaller lesion could be missed due to heavy duty of inspecting large number of animals each day and limited time available for the examination of each tissue. ${ }^{10}$ Furthermore, a lack of competence in meat inspection training could be another reason for inefficiency of the service as most of the personnel lack adequate training in the area of meat inspection. ${ }^{55,56}$ Studies conducted so far have confirmed the presence of the disease based on abattoir meat inspection. The prevalence rate of $M$. bovis in cattle has been found to differ from place to place. ${ }^{56}$ The highest and lowest prevalence of $M$. bovis was recorded in Adama $(24.7 \%)^{17}$ and Addis Abeba $(1.5 \%)^{14}$ respectively. The prevalence of $M$. bovis reported from several city abattoirs are summarized in Table 7. Several reports have shown that, tuberculous lesions were predominantly detected in mediastinal lymph nodes and bronchial lymph nodes in the thoracic cavity. ${ }^{17,27,55}$ However, the lesions were also detected from abdomen (Mesenteric lymph node) region, lymph nodes of head region and from the carcass.

Table 7 Prevalence of bovine tuberculosis detected by abattoir meat inspection

\begin{tabular}{|c|c|c|}
\hline City abattoirs & Prevalence (\%) & Reference \\
\hline Adama & 24.7 & Demelash et al.,.18 \\
\hline Adama & 6.79 & Terefe, 2012 \\
\hline Addis Ababa & 1.5 & Asseged et al.., 16 \\
\hline Addis Ababa & 15.2 & Demelash et al.., ${ }^{18}$ \\
\hline Akaki & 5.83 & Ewnetu et al., ${ }^{58}$ \\
\hline Awassa & 8.8 & Demelash et al.., ${ }^{18}$ \\
\hline Butajira & 9 & Namomsa et al., .80 \\
\hline Dilla & 2.6 & Gebrezgabiher et al..92 \\
\hline Melge-Wondo & 4.5 & Demelash et al.., ${ }^{18}$ \\
\hline Nekemte & 5.9 & Mezene et al., ${ }^{127}$ \\
\hline Sululta & 3.5 & Biru et al.,79 \\
\hline Yabello & 4.2 & Demelash et al., 18 \\
\hline
\end{tabular}

\section{Mycobacterium Bovis infection in wildlife}

The emergence of newly recognized diseases in wildlife is the result of complex, and sometimes unintended, interactions between wildlife, domestic animals and humans, in terms of host ecology, pathogen and environment. ${ }^{57}$ These interactions include factors such as translocation or introduction of wildlife to new ecosystems, encroachment of human populations on traditiona wildlife habitat, supplemental feeding of wildlife and contact with infected livestock can infect wildlife. ${ }^{10}$ Infection of wild animals by M. bovis, is raising concern worldwide. ${ }^{58}$ Wild animals are susceptible to infection with many of the same disease agents that afflict domestic animals. ${ }^{55}$ Transmission of M. bovis from domestic animals to wildlife (spillover) and subsequent transmission from wildlife back to domestic animals (spillback) is common in several regions of the world. This transmission between domestic and wild animals requires either direct contact or indirectly through shared environment. They can also get infection from other wild animals. In carnivores and scavenging wildlife species (which is a characteristic of spill over hosts) infection per os is an important route of infection. ${ }^{56}$ Mycobaterium bovis has been isolated from different maintenance and spillover hosts of wildlife species in many African countries. Extensive studies conducted in the Kruger National Park of South Africa have shown the infection of $38 \%$ of the buffalos with strains of $M$. bovis. Within the same area, BTB has been diagnosed in lions (Panthera leo), whose main prey are buffaloes. ${ }^{60,61}$ In addition, a recent study conducted in Zambia has shown a prevalence of $27.7 \%$ of Bovine TB in the lechwe. ${ }^{62}$

Ethiopia is a home to 255 wild mammal species, of which 31 are endemic and 38 are listed on the International Union for Conservation of Nature's Red List of Threatened Species. ${ }^{62}$ The rapid intensification of the human-livestockwildlife interaction in Ethiopia is fueled by rapid human population growth, massive land degradation, and recurrent drought and presents a potential risk of disease transmission. ${ }^{24}$ Recently, studies conducted in some parts of our country (Welega, Awash, Babille, Bale Mountains, and South Omo) have identified a high prevalence of the non-tuberculous mycobacteria in wildlife. ${ }^{24}$ reported that 20 out of 87 tested animals (23\%) were serologically positive for Bovine TB and acid-fast bacilli were cultured from 29 of 89 animals (32.5\%). However, none of the cultured acid-fast bacilli yielded mycobacteria from the MTBC. Moreover; the status of the M. bovis infection in Ethiopian wildlife populations has not yet confirmed from the study conducted so far. ${ }^{25}$ This is may be due to problem in diagnostic facilities, number of animals tested and geographical condition where they are localized.

Lesser kudus (60\%), mountain nyalas (40\%), buffaloes (33\%), bushbucks $(25 \%)$ and elephants $(25 \%)$ were among the wildlife species from which acid fast positive rates were mainly isolated. Mycobactarium terrae, Nocardia testacea, M. avium M. paratuberculosis, M. vaccae were some of the isolated species of environmental mycobacteria, where $M$. terrae was the most frequently identified one. ${ }^{24}$ In Africa, M. terrae and M. avium was isolated from wildlife in Tanzania ${ }^{63}$ and M. vaccae in the Republic of South Africa. ${ }^{56}$ On the other hand, in Tanzania and Ethiopia, M. terra was shown to be a pathogen, associated with granulomatous lesions in cattle and in humans. ${ }^{64}$

\section{Mycobacterium bovis infection in human}

Zoonotic diseases are responsible for most (60.3\%) emergent diseases of humans. Moreover, $71.8 \%$ of emerging pathogens are of wildlife origin or have an epidemiologically important wildlife host ${ }^{65}$ Zoonotic tuberculosis is one of the many sequels of the adaptability of Mycobacterium species in different hosts. Mycobaterium bovis infections may be maintained within livestock populations and within wildlife populations, whereas human infections result from pathogen spillover from animals and very rarely from human-to-human transmission. ${ }^{66}$ Transmissions of TB from cattle to humans mostly occur through the consumption of unpasteurized milk, eating infected raw meat and close contact to infected animals. ${ }^{67}$ Exposure to aerosol-borne infection with M. bovis from cattle remains highest in farmers, veterinary staff and slaughterhouse workers. ${ }^{68}$ Transmission of $M$. bovis from humans back to cattle was also reported in Switzerland in $1998{ }^{69}$ Wildlife is also increasingly described as a source for $M$. bovis in humans that have close contact with infected animals, such as hunters (in North America) and game farmers. ${ }^{70,71}$ However, no cases of Bovine TB spillback from wildlife to livestock has been confirmed. ${ }^{72}$ Tuberculosis is among the most devastating human infectious diseases throughout the world. The public health importance of animal TB was recognized by WHO early in its 1950 report of the Expert Committee on Tuberculosis. ${ }^{73}$ Cases of TB can be classified as pulmonary and extra pulmonary (EPTB). Pulmonary TB accounts for $85 \%$ of all TB cases whereas EPTB represents $15 \%$ of all TB cases in the world and $12 \%$ of all TB in high burden cases. Human TB occurs in the EPTB form in particular are suggestive of infections due to M. bovis. ${ }^{65}$ Tuberculous lymphadenitis (most common), TB of the spine or joints and TB of the serous membranes are the most common forms of EPTB. ${ }^{74}$ Tuberculosis caused by $M$. bovis is clinically indistinguishable from TB caused by M. tuberculosis. ${ }^{11,75}$ In developed countries, eradication programs have reduced or eliminated animal tuberculosis in cattle, and human disease is now rare. However, the disease is still common in developing countries. ${ }^{76}$ In developing countries, the human population has a greater vulnerability due to poverty, HIV and reduced access to health care. ${ }^{38}$ The proportion of which $M$. bovis contributes to the total of TB cases in humans depends on the prevalence of the disease in cattle, socioeconomic conditions, consumer habits, practiced food hygiene and medical prophylaxis measures. ${ }^{55}$ In addition, identifying the 
burden of $M$. bovis infection requires accurate diagnosis. Even though it is the primary tool for diagnosing of TB nowadays, determining the exact percentage of $M$. bovis in human TB cases based on the sputum smears is difficult. ${ }^{38}$ In general, the role of $M$. bovis in causing TB in humans has not been studied adequately. ${ }^{74}$ Ethiopia is the country with the highest TB cases and has a yearly incidence of 341 of all forms TB cases/100,000 population. ${ }^{74}$ The prevalence and mortality of Tuberculosis of all forms is estimated to be 546 and 73 per 100,000 populations respectively. According to latest estimates, among the 22 high TB burden countries that account for $81 \%$ of estimated cases, Ethiopia ranks $7^{\text {th }} \cdot{ }^{20,74}$ However, very few studies have been conducted on isolation of $M$. bovis from humans TB cases in Ethiopia so far. In Ethiopia particularly in rural areas, most people have lack awareness about the disease, drink raw milk and do have extremely close attachment with cattle (such as sharing shelter) that intensifies the transmission and spread of the disease..$^{38}$ In addition, most people of the rural areas drink raw milk. ${ }^{38}$ Even in urban areas, $82 \%$ milk is supplied unpasteurised to consumers. ${ }^{11}$ Tigre et al. ${ }^{76}$ Mohammed et al. ${ }^{77}$ Biru et al. ${ }^{78}$ and Namomsa et al. ${ }^{79}$ were reported that $85.7 \%, 81.8 \%, 79.3 \%$ and $89.5 \%$ of people consume raw milk respectively. In countries where BTB in cattle is still highly prevalent, pasteurisation is not widely practiced and/or milk hygiene is insufficient, usually estimated to be about $10 \%$ to $15 \%$ of human tuberculosis is considered to be caused by M. bovis. ${ }^{80}$ Human TB cases due to M. bovis mainly takes place through drinking raw milk and the infections occur in the extra-pulmonary form in the cervical lymphadenitis form in particular. ${ }^{74} \mathrm{With}$ respect to this, World Health Organization ${ }^{20}$ reported that TB lymphadenitis in cervical lymph nodes accounts for approximately $33 \%$ of all new cases in Ethiopia, which is greater than the global average of $\approx 15 \%$. $\operatorname{Kiros}^{20}$ also demonstrated that out of 7138 human patients with tuberculosis, $38.4 \%$ were found with EPTB and the proportion of patients with EPTB was significant in patients who have close contact with cattle and in those who frequently used to drink raw milk in particular. Similarly Asseged et al., ${ }^{24}$ have also demonstrated that, more than $30 \%$ of TB patients have EPTB and the majority of them were directly or indirectly in contact with cattle, which suggests the possible association that may exist between EPTB and $M$. bovis. The prevalence of EPTB identified in Ethiopia in the year 1999-2007 G.C is summarized in Table 8. In Ethiopia, Teshome, ${ }^{32}$ Kiros, ${ }^{18}$ Ameni and Erkihun, ${ }^{22}$ Elias et al.,${ }^{26}$ and Biru et al. ${ }^{78}$ detect $M$. bovis from raw milk. The isolation rate of $\mathrm{M}$. bovis from symptomatic human patients in specific studies was $6.9 \%$ in Uganda,${ }^{81} 5 \%$ in Nigeria $^{82}$ and between 0 and $2.5 \%$ in Latin American countries ${ }^{83}$ Few studies undertaken in Ethiopia also isolated $M$. bovis from human sputum and fine needle-aspirate samples. This isolation has shown that, the role of $M$. bovis in causing human TB cases seemed to be significantly important. ${ }^{74}$ In addition, Ameni and Erkihun ${ }^{21}$ and Elias et al., ${ }^{26}$ were isolated M. tuberculosis from milk of reactor cows. The presence of both a human TB patient and reactor cattle in a household could indicate that either the human TB patient was a source of infection for the cattle or vice versa ${ }^{84}$ It is well established that cattle infected with $M$. bovis can excrete the bacillus in their milk. However, it is not likely that cattle infected with $M$. tuberculosis would excrete the bacillus in their milk since they rarely develop TB due to $M$. tuberculosis. The other possible source of $M$. tuberculosis in milk is contamination by the cough spray from infected farmers during milking. ${ }^{84}$

On the other hand, assessment of the knowledge of cattle owners about the disease and its zoonotic potential was conducted in different parts of the country. Ameni et al., ${ }^{7}$ showed that $30.8 \%$ of the cattle owners knew that Bovine TB is zoonotic. Study conducted by Ameni \& Erkihun ${ }^{22}$ demonstrated that $35 \%$ of the respondents knew about bovine TB while only $32 \%(121 / 378)$ were aware it could be transmitted from cattle to humans. Biru et al., ${ }^{78}$ also found that only $6.9 \%$ of farm attendants had awareness about the existence of Bovine TB and $10.3 \%$ knew that milk and meat could be a source of Bovine TB infection. Although milk borne infection is the main cause of non-pulmonary tuberculosis in human, contaminated meat can also play its own role for the transmission of M. bovis. ${ }^{35}$

\section{Risk factors conducive to the spreading of Mycobacterium Bovis}

Several risk factors have been suggested for the spread of M. bovis so far. ${ }^{85}$ Risk factors will vary across regions due to factors such as differing farm structures and management practices, M. bovis infection control and eradication programmes, regional TB incidences, wildlife densities and the relative importance of specific risk factors within individual areas. ${ }^{86}$ They can broadly be separated into genetic and non-genetic (environmental), which act jointly to influence susceptibility of the hosts. ${ }^{87,88}$ Risk factors can vary based on the susceptibility hosts involved.

\section{Risk factor for cattle}

In cattle, risk factors for bovine TB can be classified as animal level and herd level. ${ }^{88}$ Among these, some of the animal level and herd level risk factors identified in our country are discussed as follows.

Animal level: Animal level risk factors are cattle breeds, genetic resistance, physiological state of the animal, age, sex, stress, concurrent infection, immune status and body condition score (BCS). ${ }^{26,32,89}$ Several past and recent studies have shown that susceptibility to bovine TB can vary between cattle breeds with suggestions that indigenous zebu cattle are more resistant to BTB than exotic breeds. ${ }^{90}$ This fact is substantiated by the lower prevalence recorded in several studies and it is evident where European breeds of cattle have been used to establish a dairy industry. Genetically improved cattle may suffer more severely from deficient housing and malnutrition and thus be more prone to infection. ${ }^{91}$ Studies conducted in different areas of our country also confirm variation in susceptibility to bovine TB among cattle breeds. Ameni et al., ${ }^{22}$ Elias et al., ${ }^{26}$ Dinka and Asmamaw, ${ }^{44}$ Zeru et al., ${ }^{91}$ Romha et al.,${ }^{92}$ have reported that, there is statistically significant difference $(\mathrm{P}<0.05)$ prevalence of bovine $\mathrm{TB}$ among exotic, cross and zebu breed where exotic and cross breeds were observed with high prevalence of BTB as compared to zebu cattle breed. One of the main animal risk factor identified by numerous studies in both developed and developing countries is the age of animals. The duration of exposure increases with age. Several studies carried out in Tanzania, Zambia and Chad have shown that older animals are more likely to have been exposed than younger ones. ${ }^{60,65,82}$ Animals might get infected at a young age, but only express the disease clinically when they are adults. Mycobacteria have the ability to remain in a latent state for a long period before reactivation at an older age. In contrast to this, Demelash et al., ${ }^{17}$ reported high disease prevalence young animals as compared to middle age group. Ameni and Erkihu ${ }^{21}$ also found fewer reactor animals were recorded in the younger age groups. This may be related to the development of infection mainly through ingestion of infected milk, in addition to aerosol exposure. Furthermore; as animals become older (above 5years), immune response also get depression; as a result animals commonly show lower reaction to tuberculin tests. ${ }^{93}$ In Ethiopia, Elias et al., ${ }^{26}$ Tsegaye et al., ${ }^{27}$ Gumi et al., ${ }^{31}$ Firdessa et al., ${ }^{14}$ Mamo et al. ${ }^{29}$ Namomsa et al. ${ }^{79}$ Gebrezgabiher et al., ${ }^{91}$ found that, statistically significant difference prevalence among age groups where higher prevalence of BTB was observed in older animals than younger ones. Gender mostly appears as a risk factor in published African studies. ${ }^{85}$ Gender-linked factors are probably related to management practices or behavioral habits; males and females are managed differently, both in developed and developing countries. ${ }^{94}$ Males have potentially more contact with other herds during breeding, which may increase their risk. ${ }^{85}$ Study conducted in Tanzania revealed that male cattle were significantly more affected by bovine TB than female animals; because they are mostly used as oxen and kept longer in the herd than females ${ }^{89,95}$ reported high prevalence of BTB in male cattle than female. In developed countries, dairy cows usually reach an older age than males because of their role in calving and milk production. Female cattle are usually confined in a barn and kept long for production purpose which may facilitate infection and acquisition of the disease. Moreover, dairy cows experience greater production stress and gathering of cattle during milking increases the risk of transmission as shown by bovine TB transmission modeling in New Zealand. ${ }^{94}$ Study conducted in Uganda revealed significantly more females positive to the skin test than males. ${ }^{96}$ In Ethiopia, Elias et al. ${ }^{26}$ Mamo et al., ${ }^{29}$ Biru et al.,${ }^{79}$ Zeru et al.,${ }^{91}$ found statistically significant difference $(\mathrm{P}<0.05)$ prevalence of bovine $\mathrm{TB}$, which was higher in female than male animals. In addition to management practices or behavioral habits, variation in disease prevalence between sexes of the animal can also be related with sample size problem. ${ }^{79}$ Factors associated with bovine TB also differed statistically according to body condition categories. Low BCS was associated with increased risk of tuberculin reactivity in a cross sectional study in Zambia. ${ }^{97}$ Study carried out in Tanzania also suggested that, skin test reactors animals might have a poor BCS as a consequence of an advanced stage of bovine TB. ${ }^{89}$ Elias et al., ${ }^{26}$ Mohammed et al., ${ }^{78}$ Biru et al., ${ }^{79}$ Namomsa 
et al., ${ }^{80}$ and Zeru et al., ${ }^{91}$ were found statistically significant difference $(\mathrm{P}<0.05)$ prevalence of $M$. bovis in Ethiopia. According to the study reports, higher bovine tuberculin reactivity was observed in animals with poor body condition as compared to those with good BCS. However, in cross-sectional studies, it is difficult to know the initial status of animals and this challenge to decide whether BTB has caused poor body condition in animals or animals with poor BCS are more susceptible to the disease. The real impact of BCS should be the subject of directed studies dealing with diet restriction. ${ }^{89,79}$ Animal's resistance to tuberculosis is reduced by a shortage of feed and/or unbalanced diet, attributable to a deficiency of proteins, minerals and vitamins in the diet. ${ }^{52}$ In contrast to the above results, Ameni and Erkuhin ${ }^{22}$ and Regassa et al. ${ }^{96}$ were found higher prevalence of the disease in animals with good body condition than poor body conditioned animals. On the other hand, during abattoir meat inspection animals, Demelash et al., ${ }^{17,95}$ Gebrezgabiher et al., ${ }^{80}$ Namomsa et al., ${ }^{81}$ and Zeru et al. ${ }^{92}$ were found that animals with medium and good body condition were less likely to have tubeculous lesions than those with poor body conditions. Although it is not commonly reported in our country, physiological state of the animal is also considered as one of the animal risk factor. ${ }^{26}$ The physiological and immunological state of an animal, including the degree of environmental stress being experienced at the time, could strongly influence the course of tuberculosis. ${ }^{98}$ Cosivi et al. ${ }^{75}$ reported that, the longer productive situations such as frequent pregnancies and high milk yields expose dairy cows to erogenous infection. Similarly, Wood et al. (1991) have also indicated that pregnant animals show lower reactivity as a result of stress induced immune suppression. This could be because animals lose sensitivity to tuberculin shortly before and after calving. ${ }^{96}$ In Ethiopia, Ameni \& Erkuhin ${ }^{22}$ were found significant variation in prevalence $(\mathrm{P}<0.05)$ in relation to reproductive status.

Herd level: Risk factors at herd level are herd size, types of farming practice and housing of cattle, geographical origin, history of bovine TB in the herd and human antecedent of tuberculosis in the household, contact between animals and with wildlife reservoirs, introduction of cattle in a herd, herd movements and trading, lack of performance of diagnostic tests, the use of hired/shared bulls, manure and environmental persistence of $M$. bovis ${ }^{64,24,86,88}$ Studies carried out in several parts of the world, both in developed and developing countries, identified herd size as one of the major BTB herd-level risk factors. ${ }^{64}$ O'Reilly and Daborn ${ }^{37}$ also suggested that, the transmission of BTB from cattle to cattle is largely influenced by herd size; the larger the herd size the greater the chance of transmission. When larger proportion of the study animals was grazing in the field, the level of confinement is reduced to a certain degree, which in turn minimizes the rate of infection in the herd. ${ }^{37}$ On the other hand, since skin test specificity is not perfect, if herd size increases, the probability of a false positive reactor will be greater. ${ }^{3}$ In Ethiopia, Firdessa et al., ${ }^{14}$ Ameni and Erkuhin, ${ }^{22}$ Elias et al., ${ }^{26}$ Tsegaye et al.. ${ }^{27}$ Romha et al., ${ }^{46}$ Biru et al.,,${ }^{79}$ and Zeru et al., ${ }^{91}$ were observed statistically significant difference $(\mathrm{P}<0.05)$ prevalence of $M$. bovis where both individual animal and herd prevalence were found higher in large and medium herd size as compared to small herds. According to literature, in some intensive dairy farms of our country, particularly in those having large herd size, the prevalence of the disease in individual animal and herd level could be rises up to $(89.9 \%)$ and $(100 \%)$ respectively. ${ }^{14}$ Animal husbandry conditions are also a major influence on the prevalence of BTB. ${ }^{89}$ Exotic dairy cows are usually kept under intensive conditions. Intensive farming systems promote close contact between animals, overcrowding and stress in animals, thereby favouring the spread of M. bovis. ${ }^{3-22}$ Cosivi et al., ${ }^{75}$ reported that, the highest incidence of BTB is generally found in areas where intensive dairy systems are practiced. Studies conducted in different parts of our country have also shown that, there is statistically significant difference $(\mathrm{P}<0.05)$ prevalence of BTB between farming systems. According to these study results, higher skin-test prevalence was observed in cattle kept under intensive conditions than those kept under extensive conditions. $22,26,14,91$ This would make extensive farming systems safer than zero grazing and more effective in preventing transmission of BTB.$^{38}$ Moreover; Radostits et al..${ }^{3}$ were found a significant association between respiratory pathology and reactivity to tuberculin test, which could indicate that inhalation is the most common route of infection into housed cattle. In addition, some study results of postmortem conducted in different abattoirs can also support this..$^{14}$ The localisation of lesions in infected animals can determine the route of infection (De Lisle et al., 2001). Ewnetu et al., ${ }^{56}$ and Namomsa et al.. ${ }^{80}$ Gebrezgabiher et al.. ${ }^{91}$ were found tuberculous lesions in the lung and associated lymph nodes at the proportion of $67.7 \%, 69.8,75 \%$ and $62.5 \%$ respectively. O'Reilly and Daborn ${ }^{37}$ and Corner ${ }^{53}$ were also reported tuberculous in the lung and associated lymph nodes at the proportion of that $68.5 \%$ and $90 \%$ respectively, suggesting that TB in cattle primarily involves the pulmonary system. Contrary to this finding, Tsegaye et al., ${ }^{27}$ found $94.5 \%$ of the lesions in mesenteric lymph nodes in animals that kept on pasture. Ameni et al. ${ }^{22}$ also reported that, mesenteric lymph node lesions were more often found in grazing animals compared to animals kept indoors.

Under the nomadic conditions, the risk of exposure to $M$. bovis also increased significantly by creating multiple herd contacts and increasing the total herd size. ${ }^{7}$ Nomadic transhumance relies on the movement of livestock to follow grazing and water over considerable distances following seasonal changes. Gumi et al. ${ }^{30}$ were observed significant difference in prevalence between herds' drinking water from river to stagnant water sources during the main dry season, which may be due to aggregation of large number of different livestock from different pastoral households around limited watering points facilitating BTB transmission either directly between animals or by contaminated pastures and water sources. However, in the most cases of the traditional animal husbandry system of Ethiopia, animals are kept in open-air even in the night, which is expected to minimise the rate of transmission of M. bovis and this is one evidence for low prevalence of the disease in these areas. ${ }^{78,91}$ The herd prevalence of BTB also varied significantly based on the management conditions and many study reports have shown higher infection rates in farms under poor management conditions. ${ }^{74}$ Elias et al. ${ }^{26}$ Romha et al. ${ }^{46}$ and Zeru et al..,91 were observed statistically significant difference $(\mathrm{P}<0.05)$ prevalence, where cattle under poor management condition were more likely to be infected with BTB as compared to cattle under good management condition. Geographical location is also one of the herd level risk factor that determines the prevalence of the disease. Tsegaye et al.,27 Mamo et al. ${ }^{29}$ Gumi et al. ${ }^{31}$ Dinka and Asmamaw, ${ }^{46}$ Demelash et al. ${ }^{53}$ and were found significant difference prevalence of the disease in cattle from different geographical origin.

Mixing or introduction of new cattle from different herds is common in Africa, increasing contact between animals. Purchase of animal in a BTB free herd is one of the major risk factors for introducing the disease, as suggested by studies carried out in the UK, Michigan, Italy and Tanzania ${ }^{89}$ In Ethiopia, Tschopp et al., ${ }^{21}$ found statistically significant difference prevalence between purchase of cattle and presence of other livestock in the herd, where high prevalence was observed in purchased cattle. Furthermore, the risk factor related with history of BTB outbreak in the herd and human antecedent of $\mathrm{TB}$ in the household is probably primordial in dairy herds, where animals often remain in the same herd for severalyears. ${ }^{63}$ Study conducted by Ameni and Erkuhin $^{22}$ have demonstrated a significant $(\mathrm{P}<0.01)$ association between the presence of reactor cattle and human TB cases in a household. Similarly, Regassa $^{34}$ and Tamiru et al., ${ }^{25}$ were reported that cattle owned by tuberculous patients had a higher prevalence $(24.3 \%)$ and $(1.36 \%)$ than cattle owned by non-tuberculous owners with $(8.6 \%)$ and $(0.56 \%)$ respectively.

\section{Risk factor for wildlife}

Although no M. bovis infections have been reported in Ethiopian wildlife population so far, reports from different parts of the world have demonstrated several risk factors for the presence of the disease in wildlife. Direct contact or sharing of environment with domestic cattle, the extent of the disease prevalence within the region/country or within domestic animal reservoir host, herd size (wildlife densities) and previous history of M. bovis in the wildlife populations are among the potential risk factors. ${ }^{26-63}$ The presence of the aforementioned animals in different wildlife reserves may have an epidemiological role in the spread of the disease among other wild and domestic animal. ${ }^{99}$ On the other hand, in Ethiopia, as wildlife habitats are not fenced, there is intensive interaction between a fast-growing human population and livestock and wildlife competing for scarce grazing land. Wildlife and, in particular, herbivores sharing pastures with cattle might therefore be at risk for bovine TB transmission. ${ }^{100}$ With respect to this, Mamo et al., ${ }^{29}$ have reported that, in Amibara district of Afar pastoral region, domestic animal were sharing grazing land in close proximity with wildlife in the area where wild animals lives (in and around Awash National Park). This suggests that there 
is a possible exposure for potential risk of disease transmission to wildlife populations in Ethiopia.

Risk factor for human: The main risk factors which contribute to the acquisition $M$. bovis infections in both urban and rural human populations are poverty, malnutrition, HIV infection, illiteracy, the consumption of raw milk (unpasteurised milk), uncooked or poorly cooked meat, work condition and close contact to livestock and using cow dung for plastering wall or floor. ${ }^{74,89}$ The habit and tradition of consumption raw milk and meat in Ethiopian societies is the main risk factors for M. bovis infection in human. ${ }^{34,38} \mathrm{Kiros},{ }^{18}$ Ameni and Erkuhin, ${ }^{22}$ Elias et al., ${ }^{26}$ Teshome, ${ }^{32}$ and Biru et al., ${ }^{79}$ detect M. bovis from raw milk and confirm the existing problem and the potential risk of the infection in humans. Cases of human TB of animal origin will continue to pose a serious public health problem, especially in areas where raw milk or its products are commonly consumed. ${ }^{74}$ Nowadays many developing countries have intensified their livestock production to meet the growing demand for food security. This intensification promotes close physical contact between the owner and his or her cattle, especially at night and thus facilitates the transmission of bovine TB as zoonosis. In addition, there is a habit of chewing and spitting tobacco to their cattle among Ethiopian farmers. This led to a higher risk of transmission for $M$. tuberculosis as well as for M. bovis at the human-livestock interface through inhalation of the cough spray from infected animals or transmission of $\mathrm{M}$.tuberculosis from human to cattle as the organism can spread to the animal..$^{21,101}$ Tuberculosis and other mycobacterial infections are major opportunistic infections in the HIV /AIDS infected individuals, while HIV/AIDS is a major predisposing factor for TB through accelerating the progression from primary infection to disease, increasing the reactivation rate of TB and the re-infection rate. ${ }^{75}$ It is estimated that 50 to $60 \%$ of HIV infected people will develop TB disease in their lifetime in contras with HIV negative persons, whose lifetime risk is only $10 \%{ }^{73}$ In addition, poverty, malnutrition also play own role in inducing infection. Families with low income often face malnutrition which, when associated with the burden of HIV/AIDS infection, increases susceptibility to various infectious diseases. ${ }^{75}$ Professional occupation or workers such as, abattoir workers, veterinarians and laboratory technicians, animal care taker in zoos and those who are working in animals reservations and at national parks can also acquire the infection in due course of regular work. ${ }^{67}$

Economic importance of Mycobacterium Bovis: Mycobaterium bovis has been widely distributed throughout the world and it represents a very significant economic and public health problem in numerous countries in both developed and the developing world. ${ }^{5}$ Consequently, most developed nations have embarked on campaigns to eradicate $M$. bovis from the cattle population or at least to control the spread of the infection. ${ }^{82}$ In developed countries, although tuberculosis is eliminated in cattle, the disease still has a major economic impact, mainly due to the existence of a permanent wildlife reservoir that reduces the efficiency of control strategies. For instance, in the United Kingdom, where badger and other wildlife such as deer remain an important source of infection for livestock, approximately $£ 100$ million is spent annually in efforts to control the disease. Republic of Ireland and New Zealand also spent approximately 35 and 13 million US \$ annually for disease control. ${ }^{102}$ In Argentina, the annual loss due to bovine TB is approximately US\$63 million. ${ }^{74}$ Although the disease has zoonotic threat, economical and financial burden to society, its cost has rarely been assessed and is largely unknown for Africa. ${ }^{103}$ Animal tuberculosis is a disease of high economic relevance within the context of livestock farming as it directly affects animal productivity. The disease considerably reduces milk and meat production of infected animal and affect animal reproduction as well as it reduce pulling power in traditional farming system. ${ }^{35}$ Infected animal loses 10 to $25 \%$ of their productive efficiency. Direct losses due to the infection become evident by decrease in 10 to $18 \%$ milk and $15 \%$ reduction in meat production.$^{97}$ The culling loss is estimated to be $30-50 \%$ of the difference between the values of a dairy or beef breeding cow and its value at slaughter. ${ }^{22}$ Moreover, national and international trade (market restrictions) and other economic sectors may be indirectly affected by the disease. ${ }^{36}$ Tuberculosis has also an economical and financial burden to society human health costs. The disease become is an obstacle to socio-economic development; $75 \%$ of people affected by TB are within the economically productive age group of $15-54$ years. This may have a negative influence on the national economy. ${ }^{33,73}$ Although the economic importance and public health significance of tuberculosis has been established in many countries, the economic impact of $M$. bovis on cattle productivity, bovine TB control programmes and other related economic effects of the disease are not yet well documented or studied in Ethiopia. ${ }^{36}$ Only few abattoir meat inspection surveillances have shown the economic loss due to condemnation of total or partial carcass and organs. According to Gezahegne, ${ }^{102}$ a report from eight export abattoirs showed a prevalence of $0.8 \%(978 / 144487)$ of slaughtered animals, in which the whole carcasses of the infected animals were condemned. Asseged et al., ${ }^{15}$ also demonstrated that, based on the tenyears retrospective analysis of the detection of tuberculous lesions in the Addis Ababa abattoir, there was a cause of $0.028 \%$ for whole carcass condemnation. Furthermore, study results of Shitaye et al. ${ }^{16}$ conducted in Addis Ababa and Debre-Zeit abattoirs ${ }^{35}$ indicated that, causes condemnation of carcasses and/or organs due to tuberculous lesions found to be highly significant economically. According to the study reports, a prevalence of $0.052 \%$ (695) and $0.001 \%$ (11) was observed in cattle and shoats respectively, and causes the whole animal's carcass condemnation. Mycobaterium bovis infections in wildlife can affect the ecosystem; moreover, the disease constitutes a threat to endangered species and can hamper BTB eradication and control schemes in domestic cattle. ${ }^{11}$

Control of tuberculosis: The effective control and eradication of $M$. bovis depend on identifying and isolating potential sources of infection. ${ }^{104}$ Limiting the number of receptive individuals using Bacillus Calmette-Guérin (BCG) vaccination and decreasing the number of infected animals through test-andslaughter policy are commonly used methods for control and eradication of TB. ${ }^{105}$ Although test-and-slaughter policy is guaranteed to eradicate tuberculosis from domesticated animals, the policy has a negative economic impact. ${ }^{71,16}$ As a result, control of bovine TB in cattle through the test-andslaughter policy is not yet established in Ethiopia. ${ }^{21}$ Control strategies are mostly limited to the inspection of carcasses at slaughterhouses. ${ }^{51}$ Certain few attempts have been also undertaken in government state farms in particular. For example, culling and slaughtering of the positive reacted cattle based on tuberculin skin testing results. ${ }^{106}$ Most commonly culling of infected animals (especially in government owned farms) and improving sanitary and hygienic standards in other dairy farms is the actual undergoing control measure of BTB infection. Vaccination of cattle using BCG vaccine is another possible strategy for control of bovine TB. Although BCG vaccination confers poor protection in animal and interferes with tuberculin test, cattle TB vaccination has some of the qualities required for a veterinary vaccine (excellent safety profile and cost-effective control strategy) in developing countries where other control strategies are difficult and expensive to implement. ${ }^{22,52}$ Treating animals with anti-tuberculosis drugs can also reduce the number of infected animals. However, this is generally considered impracticable as it is highly uneconomic, limited drugs for treatment, prolonged drug course, hazards to humans and potential for drug resistance make treatment controversial. ${ }^{105}$ Although no $M$. bovis infections have been reported in Ethiopian wildlife population so far, proper management strategies at the domestic cattle and wildlife interface are very important. Animal husbandry practices, particularly grazing lands, should be properly managed in order to reduce/prevent transmission of $M$. bovis between domestic cattle and wildlife. ${ }^{107}$ In small size parks, fences can also keep wildlife and domestic cattle separated, which efficiently reduces the risks of disease spillover. ${ }^{70}$ Bacillus Calmette-Guérin vaccination has also shown to give protection many wildlife species. ${ }^{108}$ Practical elimination of human $M$. bovis infection can be achieved with a control programme targeting only domestic animals and through BCG vaccination and employment of chemotherapy. ${ }^{109-128}$ In 1994, WHO launched the Directly Observed Treatment, Short course (DOTS) Strategy, which is the brand name of the internationally recommended strategy for TB control in human. The DOTS strategy ensures that infectious TB patients are identified and cured using standardized drug combination. ${ }^{72}$ The conventional anti-tuberculosis drugs (isoniazid, rifampicin, pyrazinamide, thiacentazone and ethambutol) are used to control and prevent the spread of the disease ${ }^{14}$ In order to reduce the risk associated with consumption of contaminated milk and meat, performing routine pasteurisation of milk and milk products and abattoir meat inspection procedures is important. Farmers and other occupationally at-risk individuals should be required to adopt appropriate measures to minimise exposure of employees. ${ }^{58}$ In general, health education is one of the pivotal means to control through sensitization and increasing awareness of the community about the epidemiological characters of the disease and other effective measures are 
being made to ensure better access throughout the country. ${ }^{73}$

\section{Conclusion and recommendations}

In Ethiopia, the endemic nature of infection due to $M$. bovis has long been confirmed. The prevalence rate of tuberculosis in livestock varies among different production system and is much higher intensive dairy farms. Most of the studies conducted on bovine TB so far have been focusing on the urban and/or peri-urban parts of the county. However, a lot of rural areas, where over $80 \%$ of the Ethiopian population is directly dependent on livestock for their daily livelihood, are not covered by adequate studies and bovine TB prevalence in these areas is largely unknown. There is no legislation on restricting cattle movements and reducing the size of herd particularly in traditional extensive production systems. The information on the disease epidemiology in general, is scarce and the current actual prevalence rate of the disease is not well established at a national level. Although bovine TB is known to be endemic in Ethiopian cattle, the status of the disease in wildlife populations, that often share the same habitat with livestock, is unknown. On the other hand, very limited studies have been conducted to identify the status of $M$. bovis in free ranging wildlife populations so far. There are no proper management strategies, which help to prevent transmission of the disease at the domestic cattle and wildlife interface. The role of $M$. bovis causing TB in humans has not been studied adequately. Currently, diagnosis of TB relies on minimal culture methods such as sputum smears. Most people particularly in rural areas have lack awareness about the existence and zoonotic potential of the disease. Collaboration between human and animal health sectors on reducing/preventing the burden of the disease is weak. The disease represents a very significant economic and public health problem; however the magnitude of economic impact of bovine TB is not yet well studied in Ethiopia. Condemnation of carcasses at slaughterhouses, test and slaughtering of tuberculin positive cattle in some government farms and pasteurisation of milk are among few attempts performed to control bovine TB. However, these measures, as compared to the cattle population of the country, are found to be insignificant.

Based on the above conclusions the following recommendations are forwarded.

i. Future researches should be focused on further investigating tuberculosis in all animal production systems especially in cattle populations managed under traditional husbandry systems.

ii. Restriction of cattle movements and reducing the size of herd particularly in traditional extensive production systems.

iii. Strict control and quarantine measures during the importation of animals and animal products.

iv. Extensive disease surveillances should be needed to assess the magnitude and importance of $M$. bovis infections in Ethiopian wildlife populations and every effort should be made to protect wildlife populations from being infected.

v. Animal husbandry practices, particularly grazing lands, should be properly managed in order to reduce/prevent transmission of $M$. bovis between domestic cattle and wildlife

vi. More sensitive and specific Rapid Test is needed to screen wildlife and test validation should probably focus on possible maintenance species or highly endangered wildlife species.

vii. There should be strong sectoral collaboration in reducing or preventing the burden of $M$. bovis infection. Institutions have stressed on the need to prevent and control tuberculosis in both humans and animals.

viii. Awareness should be created among the people in order to meet the standard hygienic requirement and to improve husbandry practices.

ix. Pasteurisation of milk and milk products should be done as routine practice most notably in rural communities.

$\mathrm{x}$. The economical and public health impact of the disease should be studied adequately at national level.

xi. Legislation that makes it obligatory to register dairy farms for enabling enforcement of control measures about any animal purchase, sales or transfer of farms should be established. These measures can be gradually expanded to the traditional integrated extensive farm systems.

xii. Dairy farms insurance that may encourage owners to cull their infected cattle after testing for bovine TB should be established within the country and disease free areas should be established and maintained.

xiii. Routine abattoir meat inspection procedures have to be made for the detection of tuberculous lesions and with the qualified veterinary staff at the slaughterhouses.

\section{Acknowledgements}

None.

\section{Conflict of interest}

Author declares that there is no conflict of interest.

\section{References}

1. Mostowy S, Inwald J, Gordon S, et al. Revisiting the Evolution of Mycobaterium bovis. J Bacteriol. 2005;187(18):6386-6395.

2. Smith NH, Gordon SV, Rua-Domenech R, et al. Bottlenecks and broomsticks: the molecular evolution of Mycobaterium bovis. Nat Rev Micro. 2006;4(9):670-681.

3. Radostits OM, Gay CC, Hinchelift KW, et al. Veterinary Medicine. A text book of the disease of cattle, sheep, pig, goat and horses. 10th ed. London; 2007.

4. Michel AL. Implications of tuberculosis in African wildlife and livestock. Ann N Y Acad Sci. 2002;969:251-55.

5. Tenguria KR, Khan FN, Quereshi S, et al. Review Article Epidemiological Study of Zoonotic Tuberculosis Complex (ZTBC).World Journal of Science and Technology. 2011;1:31-56.

6. Kaneene JB, Pfeiffer D. Epidemiology of Mycobaterium bovis. In Mycobaterium bovis infection in animals and humans. 2nd ed. Ames, Iowa 50014, USA: Blackwell Publishing; 2006:34-48.

7. Ameni G, Amenu K, Tibbo M.Bovine tuberculosis: Prevalence and risk factor assessment in cattle and cattle owners in Wuchale-Jida district, Central Ethiopia. The International Journal of Appllied Research and Veterinary Medicine. 2003;1(1):17-26.

8. De Lisle, GW, Mackintosh CG, Bengis RG. Mycobaterium bovis in freeliving and captive wildlife, including farmed deer. Revue Scientifique et Technique de l'Office International des Epizooties. 2001;20(1):86-111.

9. Thoen CO, Lobue PA, Enarson DA, et al. Tuberculosis: a re-emerging disease in animals and humans. Veterinaria Italiana. 2009;45(1):135-181.

10. Cleaveland S, Mlengeya T, Kazwala RR, et al. Tuberculosis in Tanzanian wildlife. Journal of Wildlife Diseases. 2005;41(2):446-453.

11. Renwick AR, White PC, Bengis RG. Bovine tuberculosis in southern African wildlife: a multi-species hostpathogen system. Epidemiology and Infection. 2007;135:529-540.

12. WHO, Global tuberculosis control. WHO report. 2008. p. 105-108.

13. Dye C, Scheele S, Dolin P, et al. Consensus statement. Global burden of tuberculosis: estimated incidence, prevalence and mortality by country. WHO Global Surveillance and Monitoring Project. JAMA. 1999;282(7):677-686.

14. WHO (World Health Organization). Global tuberculosis control Surveillance, Planning and Financing. WHO Report, Country Profile, Ethiopia; 2005;83-86.

15. Firdessa R, Tschopp R, Wubete A, et al. High Prevalence of Bovine Tuberculosis in Dairy Cattle in Central Ethiopia: Implications for the Dairy Industry and Public Health. PLoS ONE. 2012;7(12):e52851. 
16. Asseged B, Woldesenbet Z, Yimer E, et al. Evaluation of abattoir inspection for the diagnosis of Mycobaterium bovis infection in cattle at Addis Ababa abattoir. Trop Anim Health Prod. 2004;36(6):537-546.

17. Shitaye JE, GetahunB, Alemyehu T, et al. prevalence study of bovine tuberculosis by using abattoir meat inspection and tuberculin skin testing data, histopathological and IS6110 PCR examination of tissues with tuberculous lesions in cattle in Ethiopia. Veterinarni Medicina. 2006;51(11):512-522.

18. Demelash B, Inangolet F, Oloya J, et al. Prevalence of Bovine tuberculosis in Ethiopian slaughter cattle based on post-mortem examination. Trop Anim Health Prod. 2008;41(5):755-765.

19. Kiros Teklu. Epidemiology and zoonotic importance of bovine tuberculosis in selected sites of Eastern Shewa Ethiopia. [MSc. Thesis.] Faculty of Veterinary Medicine, University and Freie Universitat, Germany; 1998.

20. Kidane D, Olobo JO, Habte A, et al. Identification of the causative organism of tuberculosis lymphadenitis in Ethiopia by PCR. Journal of Clinical Microbiology. 2002;40(11):4230-4234.

21. WHO (World Health Organization). Global tuberculosis control: World Health Organization report. 2012.

22. Tschopp R, Schelling E, Hattendorf J, et al. Risk factors of bovine tuberculosis in cattle in rural livestock production systems of Ethiopia. Prev Vet Med. 2009;89(3-4):205-211.

23. Ameni G, Aseffa A, Engers H, et al. High prevalence and increased severity of pathology of bovine tuberculosis in Holsteins compared to zebu breeds under field cattle husbandry in Central Ethiopia. Clin Vaccine Immunol. 2007;14(10):1356-1361.

24. Tschopp R, Aseffa A, Schelling E, et al. Bovine Tuberculosis at the Wildlife-Livestock-Human Interface in Hamer Woreda, South Omo, Southern Ethiopia. PLoS One. 2010;5(8):e12205.

25. Gumi B, Schelling E, Firdessa R, et al. Low prevalence of bovine tuberculosis in Somali pastoral livestock, southeast Ethiopia. Trop Anim Health Prod. 2012;44(7):1445-1450.

26. Tamiru F Hailemariam M, Terfa W. Preliminary study on prevalence of bovine tuberculosis in cattle owned by tuberculosis positive and negative farmers and assessment of zoonotic awareness in Ambo and Toke Kutaye districts, Ethiopia. Journal of Veterinary Medicine and Animal Health. 2013;5(10):288-295.

27. Elias K, Hussein D, Asseged B, et al. Status of bovine tuberculosis in Addis Ababa dairy farms. Rev Sci Tech. 2008;27(3):915-923.

28. Tsegaye W, Aseffa A, Mache A, et al. Conventional and Molecular Epidemiology of Bovine Tuberculosis in Dairy Farms in Addis Ababa City, the Capital of Ethiopia. Intern J Appl Res Vet Med. 2010;8(2):143-152.

29. Tschopp R, Bobosha K, Aseffa A, et al. Bovine tuberculosis at a cattlesmall ruminant human interface in Meskan, Gurage region, Central Ethiopia. BMC Infect Dis. 2011;11:318.

30. Mamo G, Abebe F, Worku Y, et al. Bovine tuberculosis and its associated risk factors in pastoral and agro-pastoral cattle herds of Afar Region, Northeast Ethiopia. Journal of Veterinary Medicine and Animal Health. 2013;5(6):171-179.

31. Deresa B, Conraths FJ, Ameni G. Abattoir-based study on the epidemiology of caprine tuberculosis in Ethiopia using conventional and molecular tools. Acta Veterinaria Scandinavica. 2013;55:1-15.

32. Gumi B, Schelling E, Firdessa R, et al. Prevalence of bovine tuberculosis in pastoral cattle herds in the Oromia region, southern Ethiopia. Trop Anim Health Prod. 2011;43:1081-1087.

33. Teshome Yohanes. Occurrence and zoonotic potential of M. bovis infection in Ethiopia: epidemiological, bacteriological and molecular biological aspects. Giessen, Germany, 1993.
34. Asseged B, Lübke Becker A, Lemma E, et al. Bovine TB: a cross-sectional and epidemiological study in and around Addis Ababa. Bull Anim health Prod in Africa. 2000;48(2):71-80.

35. Regassa Alemu. Study on Mycobaterium bovis in animals and human in and around Fiche, North Shewa zone, Ethiopia. Faculty of Veterinary Medicine, Addis Ababa University, Debre-Zeit, Ethiopia. 2005.

36. Daborn CJ, Grange JM. HIV/AIDS and its implications for the control of animal tuberculosis. Br Vet $J .1996 ; 149: 405-417$.

37. Zinsstag J, Schelling E, Roth F, Kazwala RR. Economics of bovine tuberculosis. In Mycobaterium bovis Infection in Animals and Humans ( $2^{\text {nd }}$ edn) Ames, Iowa 50014, Blackwell Publishing, USA; Wobeser GA.

38. O'Reilly LM, Daborn CJ. The epidemiology of Mycobaterium bovis infections in animals and man: A review. Tubercle Lung Dis. 1995;76(Suppl 1): $1-46$.

39. Ayele WY, Neill SD, Zinsstag J, et al. Bovine tuberculosis: an old disease but a new threat to Africa. Int J Tuberc Lung Dis. 2004;8(8):924-937.

40. Hirsh CD, Zee CY. Veterinary Microbiology. USA: Blackwell science; 1999:158-164.

41. Monaghan ML, Doherty ML, Collins JD, et al. The tuberculin test. Vet Microbiol. 1994;40(1-2):111-124.

42. Collins FM. The immune response to mycobacterial infection: Development of new vaccine. Vet Microbiol. 1994;40(1-2):95-110.

43. Birhan Malede. Livestock resource potential and constraints in Somali Regional State, Ethiopia. Global Veterinaria. 2013;10(4):432-438.

44. Anonymous. Project Appraisal document on pastoral community development project. The World Bank Document. New York, USA; 2003. $114 \mathrm{p}$.

45. Laval G, Ameni G. Prevalence of bovine tuberculosis in zebu cattle under traditional animal husbandry in Boji district of western Ethiopia. Revue Méd. Vét. 2004;155(10):494-499.

46. NABC (Netherlands-African Business Council). Livestock in Ethiopia and opportunity analyses for Dutch investment. Fact Sheet: Livestock, Ethiopia; 2010.

47. Hunduma Dinka and Asmamaw Duressa. Prevalence of bovine tuberculosis in Arsi Zones of Oromia, Ethiopia. AJAR. 2011;6:3853-3858.

48. Romha G, Gebre egziabher G, Ameni G. Assessment of bovine tuberculosis and its risk factors in cattle and humans, at and around Dilla town, southern Ethiopia. Animal and Veterinary Sciences. 2014;2(4):94-100.

49. Schiller I, Oesch B, Vordermeier HM, et al. Bovine Tuberculosis: A Review of Current and Emerging Diagnostic Techniques in View of their Relevance for Disease Control and Eradication. Transboundary and Emerging Diseases. 2010;57(4):205-220.

50. FAO (Food and Agricultural Organization). Livestock production primary. Food and Agriculture Organization of the United Nations, USA; 2009.

51. Shitaye JE, Tsegaye W, Pavlik I. Bovine tuberculosis infection in animal and human populations in Ethiopia: a review. Veterinarni Medicina. 2007;52(8):317-332.

52. Biffa D, Bogale A, Skjerve E. Diagnostic efficiency of abattoir meat inspection service in Ethiopia to detect carcasses infected with Mycobacterium bovis: Implications for public health. BMC Public Health. 2010;10:462.

53. Cousins DV, Huchzermeyer HF, Griffin, et al. Tuberculosis Infectious Diseases of Livestock. Cape Town: Oxford University Press; 2014.

54. Inangolet FO, Demelash B, Oloya J, et al. A cross-sectional study of bovine tuberculosis in the transhumant and agro-pastoral cattle herds in the borde rareas of Katakwi and Moroto districts, Uganda. Trop Anim Health 


\section{Prod. 2008;40(7):501-508.}

55. Thoen C Lobue P, de KI. The importance of Mycobaterium bovis as a zoonosis. Vet Microbiol. 2006;112:339-345.

56. Michael AL, Bengis RG, Keet DF, et al. Wildlife tuberculosis in South African conservation areas: Implications and challenges. Veterinary Microbiology. 2006;112:91-100.

57. Corner LAL. The role of wild animal populations in the epidemiology of tuberculosis in domestic animals: how to assess the risk. Vet Microbiol. 2006;112(2-4): 303-312.

58. Ewnetu L, Melaku A, Birhanu. Bovine Tuberculosis Prevalence in Slaughtered Cattle at Akaki Municipal Abattoir, Based on Meat Inspection Methods. Global Veterinaria. 2012;(5):541-545.

59. Delahay RJ. The status of Mycobaterium bovis infection in UK wild mammals: a review. Vet J. 2002;164(2):90-105.

60. Bengis RG, Kriek NP, Keet DF, et al. Bovine tuberculosis in free-ranging wildlife: a review of global occurrence, pathology and epidemiology of this disease, and potential conservation implications International Wildlife TB Conference. Skukuza, Kruger National Park, South Africa; 2012.

61. De Vos, V Bengis, RG Kriek, et al. The epidemiology of tuberculosis in free-ranging Afican buffalo (Syncerus caffer) in the Kruger National Park, South Africa Onderstepoort. J Vet Res. 2001;68(2):119-130.

62. Munyeme M. Tuberculosis in Kafue lechwe antelopes (Kobus leche kafuensis) of the Kafue Basin in Zambia. Prev Vet Med. 2010;95(3-4):305-308.

63. IUCN (International Union for Conservation of Nature's). Red List of Threatened Species. 2008.

64. Cleavelan S, Shaw DJ, Mfinanga SG, et al. Mycobaterium bovis in rural Tanzania: risk factors for infection inhuman and cattle populations. Tuberculosis (Edinb). 2007;87(1):30-43.

65. Jones KE, Patel NG, Levy MA. Global trends in emerging infectious diseases Nature. 2008;451(7181):990-993.

66. Biet F, Guilloteau LA, Boschiroli ML, et al. Zoonotic aspects of Mycobaterium bovis and Mycobacterium avium-intracellulare complex (MAC). Vet Res. 2005;36(3):411-436.

67. Sunder S, Lanotte P, Godreuil S, et al. Human-to-human transmission of tuberculosis caused by Mycobaterium bovis in immunocompetent patients. J Clin Microbiol. 2009;47:1249-1251.

68. Pavlik I, Ayele WY, Parmova I, et al. Incidence of bovine tuberculosis in cattle in seven Central European countries during the years 1990-1999. Vet med. 2002;47:45-51.

69. Fritsche A, Engel R, Buhl D, et al. Mycobaterium bovis tuberculosis: from animal to man and back. Int J Tuberc Lung Dis. 2004;8(7):903-904.

70. Baker MG, Lopez LD, Cannon MC, et al. Continuing Mycobaterium bovis transmission from animals to humans in New Zealand. Epidemiol Infect. 2006;134(5):1068-1073.

71. Wilkins MJ, Meyerson J, Bartlett PC, et al. Human Mycobaterium bovis infection and bovine tuberculosis outbreak, Michigan, 1994-2007. Emerg Infect Dis. 2008;14(4):657-660.

72. De Garine-Wichatitsky M. Consequences of animals crossing the edges of transfrontier parks. In: Andersson JA, editor. Areas People Living on the Edge. New York, London. Earth scan. 2013:137-162.

73. Flamand JRB, Greth A, Haagsma J, et al. An outbreak of tuberculosis in a captive herd of Arabian oryx (Oryx leucoryx): diagnosis and monitoring. Vet Rec. 1994;134(5):115-118.

74. Senedu B, Gebreegziabher, Solomon A Yimer, et al. Federal Ministry of Health Ethiopia Tuberculosis, Leprosy and TB/HIV Prevention and Control Program Manual FMOH, Addis Ababa. Journal of Tuberculosis Research. 2008;4(1).
75. Cosivi O, Grange JM, Dabron CJ, et al. Zoonotic tuberculosis due to Mycobaterium bovis in developing countries. Emerg Infect Dis. 1998;4(1):59-70.

76. Grange JM, Yates, MD. Zoonotic aspects of Mycobaterium bovis infection. Vet Microbiol. 1994;40(1-2):137-151.

77. Tigre W, Alemayehu G, Abetu T, et al. Preliminary Study on Public Health Implication of Bovine Tuberculosis in Jimma Town, South Western Ethiopia. Global Vet. 2011;6:369-373.

78. Mohammed N, Mazengia H, Mekonen G. Prevalence and zoonotic implications of bovine tuberculosis in Northwest Ethiopia. Int J Med Med Sci. 2012;2:182-192.

79. Biru A, Ameni G, Sori T, et al. Epidemiology and public health significance of bovine tuberculosis in and around sululta district, central Ethiopia. Africn Journal of microbiology Research. 2014;8(24):2352-2358.

80. Namomsa B, Gebrezgabiher G, BiranuT, et al. Epidemiology of bovine tuberculosis in Butajira, Southern Ethiopia: A cross sectional abattoir- based study. African journals of microbiology research. 2014;8(33):3112-3117.

81. Oloya J, Opuda-Asibo J, Djønne B, et al. Responses to tuberculin among Zebu cattle in the transhumance regions of Karamoja and Nakasongola district of Uganda. Trop Anim Health Prod. 2006;38(4):275-283.

82. Cleaveland S, Shaw DJ, Mfinanga SG, et al. Mycobaterium bovis in rural Tanzania: risk factors for infection inhuman and cattle populations. Tuberculosis (Edinb). 2007;87(1):30-43.

83. Cousins DV. Mycobaterium bovis infection and control in domestic livestock Western Australia reference laboratory for bovine tuberculosis. Australia Rev Sci Tech. 2001;20(1):71-85.

84. Cook AJC, Tuchili LM, Buve A, et al. Human and bovine tuberculosis in the Monze District of Zambia - a cross-sectional study. $\mathrm{Br}$ vet $\mathrm{J}$. 1996;152(1):37-46

85. Humblet MF, Boschiroli ML, Saegerman C. Classification of worldwide bovine tuberculosis risk factors in cattle: a stratified approach. Vet Res. 2009;40(5):50.

86. Waddington K. Bovine tuberculosis and tuberculin testing in Britain, 1890-1939. Med Hist. 2004;48(1):29-48.

87. Rogers LM. Changes in badger (Meles meles) spatial organisation in Woodchester Park, south-west England. In: Griffiths H, editor. Mustelids in the Modern World. Hull, England: Hull University Press; 2000.

88. Morens DM, Folkers GK, Fauci AS. The challenge of emerging and reemerging infectious diseases. Nature. 2004;430(6996):242-249.

89. Kazwala RR, Kambarage DM, Daborn CJ, et al. Risk factors associated with the occurrence of bovine tuberculosis in cattle in the Southern Highlands of Tanzania. Vet Res Commun. 2001;25(8):609-614.

90. Otte MJ, Chilonda P. Cattle and small ruminant production systems in subSaharan Africa - A systematic review. Food and Agriculture Organization of the United Nations. Rome; 2002.

91. Zeru F, Romha G, Berhe G, et al. Prevalence of bovine tuberculosis and assessment of Cattle owners' awareness on its public health implication in and around Mekelle, Northern Ethiopia. Journal of Veterinary Medicine and Animal Health. 2004;6:160-167.

92. Gebrezgabiher G, Romha G, Ameni G. Prevalence Study of Bovine Tuberculosis and Genus Typing of its Causative Agents in Cattle Slaughtered at Dilla Municipal Abattoir, Southern Ethiopia. African Journal of Basic \& Applied Sciences. 2014;(4):103-109.

93. Laval G, Ameni G. Prevalence of bovine tuberculosis in zebu cattle under traditional animal husbandry in Boji district of western Ethiopia. Revue Méd Vét. 2004;155(10):94-499.

94. Barlow N. A simulation model for the spread of bovine tuberculosis within New Zealand cattle herds. Prev Vet Med. 1997;32(1-2):57-75. 
95. Terefe Dechassa. Gross pathological lesions of bovine tuberculosis and efficiency of meat inspection procedure to detect-infected cattle in Adama municipal abattoir. Journal of Veterinary Medicine and Animal Health 2014;6(2):48-53.

96. Regassa A, G Medhin, G Ameni. Bovine tuberculosis is more prevalent in cattle owned by farmers with active tuberculosis in central Ethiopia. Vet $J$. 2008;178(1):119-125.

97. Olson KM, Vanraden PM, Tooker ME, et al. Differences among methods to validate genomic evaluation for dairy cattle. J Dairy Sci. 2011;94(5):2613-2620.

98. Radostits OM Blood DC. Disease caused by mycobacteria IV. In: Veterinary Medicine. 7th ed. London, UK: Bailliere Tindall; 1994;7:710-740.

99. Kriek N. Bovine tuberculosis program in South Africa The impact of $M$ bovis-infected wild species Mycobaterium bovis. Infection in Animals and Humans. 2nd ed. Ames, Iowa: Blackwell Publishing Professional; 2006:238-243.

100. Buddle BM, Wedlock DN, Parlane NA, et al. Revaccination of neonatal calves with Mycobacterium bovis BCG reduces the level of protection against bovine tuberculosis induced by a single vaccination. Infect Immun 2003;71(11):6411-6419.

101. Kovalev GK. Tuberculosis in wildlife, a review. J Hyg Epidemio Microbiol Immunol. 1980;24(4):495-504.

102. Weinhaupl I, Schopf KC, Khaschabi D, et al. Investigations on the prevalence of bovine tuberculosis and brucellosis in dairy cattle in Dar es Salaam region and in zebu cattle in Lugoba area, Tanzania. Trop Anim Health Prod. 2000;32(3):147-154.

103. Hope JC, Villarreal-Ramos B. Bovine TB and the development of new vaccines. Comp Immunol Microbiol Infect Dis. 2008;31(2-3):77-100.

104. Ryan TJ, Livingstone PG, Ramsey DSL. Advances in understanding disease epidemiology and implications for control and eradication of tuberculosis in livestock: the experience from New Zealand. Vet Microbiol. 2006;112(2-4):211-219.

105. Artois M, Blancou J, Dupeyroux O, et al. Sustainable control of zoonotic pathogens in wildlife: how to fair to wildlife. Rev Sci Tech. 2011;30(3):733-743.

106. Alemu Taye. Bovine tuberculosis in Ethiopia Tropical animal health and production [MSc Dissertation]. University of Edinburgh, Centre for Tropical Veterinary Medicine, UK; 1992.

107. Martin SW, Eves JA, Dolan LA, et al. The association between the bovine tuberculosis status of herds in the East Offaly Project Area, and the distance to badger setts. Prev Vet Med. (1988-1993);31(1-2):113-125.

108. Suazo FM, Escalera AMA, Torres RMG. A review of M-bovis BCG protection against TB in cattle and other animals species. Prev Vet Med. 2003;58(1-2):1-13

109. Coldltz GA, Brewer TF, Berke KS, et al. Efficacy of BCG vaccine in the prevention of tuberculosis. J Am med Assoc. 1994;271(9):698-702.

110. Abraham Aseffa. The Wellcome Trust Bovine TB Project in Ethiopia: The Bovine TB Project Team Ethiop. J JHealth Dev. 2008;22.

111. Ameni G, Hewinson G, Aseffa A, et al. Appraisal of interpretation criteria for the comparative intradermal tuberculin test for the diagnosis of bovine tuberculosis in central Ethiopia. Clin Vaccine Immunol. 2008;15(8):1272(1988- 1993)1276.
112. CSA (Central Statistical Agency). Report on Livestock and Livestock Characteristics. Agricultural Sample Survey 2011/2012. Addis Ababa: Central Statistical Agency of Ethiopia; 2011

113. CSA (Central Statistical Agency). Report on livestock and livestock characteristics Statistical bulletin 388. Addis Ababa: Ethiopia; Agricultural sample survey 2006/07. 2007.

114. FAO (Food and Agricultural Organization). Agriculture towards Proceedings of the Food and Agricultural Organization, United Nations, Conference Report C/93/24: Rome, Italy; 2010.

115. FAO (Food and Agricultural Organization). Livestock development strategies for low income counties. Proceeding of the joint ILRI/FAO round table on livestock development strategies for low income counties. Addis Ababa, Ethiopi; 1995.

116. Firdessa R, Berg S, Hailu E, et al. Mycobacterial Lineages Causing Pulmonary and Extrapulmonary Tuberculosis, Ethiopia. Emerg Infect Dis. 2013;19(3):460-463.

117. Gobena Ameni, Ashenafi Erkihun. Bovine tuberculosis on small-scale dairy farms in Adama Town, central Ethiopia, and farmer awareness of the disease. Rev sci tech Off int Epiz. 2007;26(3):711-719.

118. Griffin JFT, Mac Kintosh CG, Rodgers CR. Factors influencing the protective efficacy of a BCG homologous prime-boost vaccination regime against tuberculosis. Vaccine. 2006;24(6):835-845.

119. Halderman M. The Political Economy of Pro-Poor Livestock PolicyMaking in Ethiopia In: Initiative P-PLP, editor Rome, Italy; 2004:1-59.

120. Johnson L, Dean G, Rhodes S, et al. Low-dose Mycobaterium bovis infection in cattle results in pathology indistinguishable from that of highdose infection. Tuberculosis (Edinb). 2007;87(1):71-76.

121. MoH (Ministry of Health). Ministry of Health, Addis Ababa, Ethiopia; 2004.

122. Munyeme M, Muma JB, Samui KL, et al. Prevalence of bovine tuberculosis and animal level risk factors for indigenous cattle under different grazing strategies in the livestock/wildlife interface areas of Zambia. Trop Anim Health Prod. 2009;41(3):345-352

123. Omer MK. A cross-sectional study of bovine tuberculosis in dairy farms in Asmara, Eritrea. Tropical Animal Health and Production. 2001;33(4):295-303.

124. Reviriego GFJ, Vermeersch JP. Towards eradication of bovine tuberculosis in the European Union. Vet Microbiol. 2006;112(2-4):101-109.

125. Thoen C. Mycobaterium bovis infection in animals and humans. Iowa: Iowa State University press; $1995.355 \mathrm{p}$

126. Wood PR, Corner LA, Rothel JS, et al. Field comparison of the interferon gamma assay and the intradermal tuberculin test for the diagnosis of bovine tuberculosis. Aust vet J. 1991;68(9):286-290.

127. Mezene W, Jibril Y, Ameni G, et al. Molecular Epidemiology of Mycobacterium Tuberculosis Complex at Nekemte Municipality Abattoir, Western Ethiopia. Sci Technol Arts Res J. 2014;3(2):167-173.

128. Gezahegne Lemma. Economical aspect of condemned organs and parts due to cystycercosis, hydatidosis, fasciolosis and tuberculosis Analysis report MoA. Addis Ababa, Ethiopia; 1991. 